\title{
Impact of Teachers' Relational Style to Teachers' Efficiency
}

\author{
Arturo R. Moreno, Elymar A. Pascual \\ elymarpascual@rocketmail.com \\ Department of Education, Nagcarlan, Laguna, Philippines 4002
}

\begin{abstract}
This paper focused on determining the relational style of the faculty and staff of Talangan National High School (TNHS), in knowing their efficiency rating, and in finding out the possible effect of relational style to efficiency rating. There are four widely accepted relational styles: the dominant, the influential, the steady and the conscientious. These relational styles are seen in offices, companies, public or private establishment, church community, or even at home. All of these four styles have strengths and weaknesses, focus, and ways of dealing with people around them. To explore on those aspects, the researcher conducted a survey on relational style of TNHS faculty and staff. The efficiency rating was obtained using the Consolidated IPCRF of the previous school year. After doing these, F-test established the significant effect of relational style to efficiency rating. It was found out that out of 32 teacher-respondents, 6 teachers or 19\% are dominant, 6 teachers or $19 \%$ are influential, 13 teachers or $40 \%$ are steady, and 7 teachers or $22 \%$ are conscientious. The average efficiency rating for dominant teacher is 3.78 (VS), for influential teachers is 3.74 (HS), for steady teachers is 3.64 (VS) and for conscientious teachers is 3.90 (VS). The F-value computed is 3.37 while the critical value is 2.95. Since F-comp is greater than critical value, the hypothesis is rejected. The relational style of teachers has something to do with their efficiency rating. If the teacher is conscientious, he or she will have a higher efficiency rating than other teachers. Based on this result and findings, recommendation to target people was given at the end of the study.
\end{abstract}

Keywords: relational style; dominant; influential; steady; conscientious; teacher; efficiency

\section{Introduction}

"One looks back with appreciation to the brilliant teachers, but with gratitude to those who touched our human feelings. The curriculum is so much necessary raw material, but warmth is the vital element for the growing plant and for the soul of the child." Carl Gustav Jung (Blue Mountain Arts, 1999)

Relating to the students is a vital part of the teaching and learning process. It's hard to effectively communicate the idea and let it remain into one's mind if the teacher and the learner are not well acquainted with each other. This is the reason why an inconsiderate teacher can hardly motivate his or her students. They will be uninterested to learn if the teacher has not yet touched their heart, and just their feeble minds.

On the other hand, a teacher who is able to show sympathy on the students would be likely to motivate his or her students to study well and give their best, now that they know their teacher understands their situation.

All of this logical reasoning about the demeanor of the students in front of their teacher is but a theory. But what can the relational style of the teacher really do with their performance as a teacher? Does their relational style have something to do with their efficiency rating? Or is it dependent on the student as well?

\subsection{Background of the Study}

Talangan National High School (TNHS) was established last 1970. It is known not only for quality education, but also for quality educators who respect and relates well with each other. That is why retirees 
share wonderful memories of years of stay in TNHS. They know how to respond to others' need and how to relate to others' way of expressing their gift and talents to God. They also understood themselves more through the strengths that they can contribute to others and through the weaknesses that they can still cope up with.

But relating with each other, or relational style, and its effect on teaching efficiency has not yet been studied or investigated. So this study came along. Through the desire of the researcher to make the understanding of the teachers about their relational style more meaningful, the researcher designed a study to test relational style against efficiency rating.

Experts show four relational styles that persons have: Dominant, Influential, Steady and Conscientious (DISC). Does relational style have something to do with efficiency rating? This study aimed at investigating on that aspect.

\subsection{Conceptual Framework}

IV

DV

\begin{tabular}{|l|l|}
\hline $\begin{array}{l}\text { Teachers' Relational Style } \\
\text { * Dominant } \\
\text { * Influential } \\
\text { * Steady } \\
* \text { Conscientious }\end{array}$ & $\begin{array}{c}\text { Teachers' Efficiency Rating } \\
- \text { as shown in the } \\
\text { Consolidated IPCRF, } \\
\text { Jan.-Dec. 2015 }\end{array}$ \\
\cline { 2 - 3 }
\end{tabular}

Figure 1. The Paradigm

The figure presents the paradigm of the study. The framework at the left includes TNHS teachers' relational style: dominant, influential, steady or conscientious. The framework at the right includes TNHS teachers' efficiency rating as evaluated by the principal last s.y. 2007-2008 as shown in the Consolidated IPCRF, Jan. - Dec. 2015. The arrow that connects the two frameworks represents possible effect of the one variable to the other.

\subsection{Statement of the Problem}

The goal of this study is to establish the effect of relational style with the efficiency of teachers in Talangan National High School.

Specifically, it sought to find answer to the following questions:

1.) What is the relational style of the teachers in Talangan National High School (dominant, influential, steady or conscientious)?;

2.) What is the efficiency rating of the teachers in TNH as evident in the Consolidated IPCRF of January-December 2015?

3.) Does relational style of teachers have something to do with their efficiency rating?

\subsection{Hypothesis}

This is a tentative solution to the problem posted at the beginning of the study:

The relational style of TNHS teachers has nothing to do with their efficiency rating. 


\subsection{Significance of the Study}

This study will be of great help to the following group of persons: well as others.

1.) Teachers - Knowing their relational style will facilitate them in understanding themselves, as

2.) School Administration - Having a good rapport with the faculty is one of the pillars for a school to have good, lasting relationship, and therefore, better service to their clients.

3.) Students - As the primary clients, students will be guided well if the teachers know how to deal with their own relational style.

4.) Parents - Parents will also be assisted well in nurturing their child at home, if the school has properly communicated what their child needs.

5.) Future Researchers - Other researchers can use the concepts that will be formulated in this study for his future endeavor, or in furthering the study already started here.

\subsection{Scope and Limitation}

The relational style of each faculty member will be evaluated by themselves, so there may be bias in terms of their personal rating. Nevertheless, the instrument to be used has a wide range of personality choices where the teachers can really evaluate themselves. Their efficiency rating was evaluated by the school head, and it is with the assumption that the latter is using an objective type of standards. This means that subjectivity is lessen, and therefore, will elicit valid conclusion if checked against teacher's relational style.

\section{Review of Related Literature}

This chapter present significant readings related to the present study, the hypothesis made as a primary solution to the question posted at the beginning of the study, the paradigm and the definition of terms as they are used in this study.

DISC.HTM (Syque, 2002-2007) has the following discussions on the four relational styles.

"This is a popular system originating in the 1920's by an American psychologist called William Moulton Marston. It measures four preferences, in which you are scored in each preference (thus resulting in a profile score across each type).

"The meanings of the DISC letters vary, according to whom you talk. Known variants are included in the table below:

Table 1. DISC Types and Their Description

\begin{tabular}{|l|l|}
\hline DISC type & Description \\
\hline $\begin{array}{l}\text { Dominant } \\
\text { (Direct, Driver, } \\
\text { Demanding, Determined, } \\
\text { Decisive, Doer) }\end{array}$ & $\begin{array}{l}\text { Independent, persistent, direct. } \\
\text { Energetic, busy, fearless. } \\
\text { Focus on own goals rather than people. } \\
\text { Tell rather than ask. } \\
\text { Ask 'What?' }\end{array}$ \\
\hline $\begin{array}{l}\text { Influential } \\
\text { (Inducement, Inspiring, } \\
\text { Impressive, Interacting, }\end{array}$ & $\begin{array}{l}\text { Social, persuasive, friendly. } \\
\text { Energetic, busy, optimistic, distractible. } \\
\text { Imaginative, focus on the new and future. }\end{array}$ \\
\hline
\end{tabular}




\begin{tabular}{|l|l|}
\hline Interesting) & $\begin{array}{l}\text { Poor time managers. Focused on people than tasks. } \\
\text { Tell rather than ask. } \\
\text { Ask 'Who?' }\end{array}$ \\
\hline $\begin{array}{l}\text { Steady } \\
\text { (Submissive, Stable, } \\
\text { Supportive, Shy, Status } \\
\text { quo, Specialist) }\end{array}$ & $\begin{array}{l}\text { Consistent, like stability. } \\
\text { Accommodating, peace-seeking. } \\
\text { Like helping and supporting others. Good listeners and } \\
\text { Close relationships with few friends. } \\
\text { Ask, rather than tell. } \\
\text { Ask 'How?' and 'When?' }\end{array}$ \\
\hline $\begin{array}{l}\text { Conscientious } \\
\text { (Cautious, Compliant, } \\
\text { Correct, Calculating, } \\
\text { Concerned, Careful, } \\
\text { Contemplative) }\end{array}$ & $\begin{array}{l}\text { Slow and critical thinker, perfectionist. } \\
\text { Logical, fact-based, organized, follows rules. } \\
\text { Don't show feelings. Private. Few, but good friends. } \\
\text { Big-picture, outlines. } \\
\text { Ask 'Why?' and 'How?' }\end{array}$ \\
\hline
\end{tabular}

"When compared to the Myers-Briggs Type Inventory, it is more behaviorally focused (Myers Briggs focuses more on the thinking processes). including:

"Just by looking closely at this, a number of preferences can be seen within the DISC types,

Table 2. Preferences of Each Relational Style

\begin{tabular}{|l|c|c|c|c|}
\hline Preference & Dominant & Influential & Steady & Cautious \\
\hline Focus on other people & & $\mathrm{X}$ & $\mathrm{X}$ & \\
\hline Independent, internal & $\mathrm{X}$ & $\mathrm{X}$ & & $\mathrm{X}$ \\
\hline Energetic and busy & $\mathrm{X}$ & $\mathrm{X}$ & & \\
\hline $\begin{array}{l}\text { Tell rather than ask (vs. } \\
\text { opposite) }\end{array}$ & & $\mathrm{X}$ & $\mathrm{X}$ \\
\hline $\begin{array}{l}\text { Imaginative, big-picture, } \\
\text { future-focused }\end{array}$ & & $\mathrm{X}$ & $\mathrm{X}$ \\
\hline $\begin{array}{l}\text { Like stability and } \\
\text { predictability }\end{array}$ & $\mathrm{X}$ & $\mathrm{X}$ & & \\
\hline Like change (vs. stability) & & $\mathrm{X}$ & $\mathrm{X}$ & $\mathrm{X}$ \\
\hline Task-oriented (vs. people) & & & & \\
\hline Flexible to changing world & & & & \\
\hline
\end{tabular}

"The DISC can be simplified in a $2 \times 2$ grid: 
Table 3. Summary of Focus and Characteristic of Each Relational Style

\begin{tabular}{|c|c|c|}
\hline & People-focused & Task-focused \\
\hline Active, Outgoing & Influential & Dominant \\
\hline Passive, Internal & Steady & Conscientious \\
\hline
\end{tabular}

"Understand the DISC type. They are quite simple and thus easy to use. Then play to the person's preferences and overall type.

"With Dominant people

- Build respect to avoid conflict

- Focus on facts and ideas rather than the people

- Have evidence to support your argument

- Be quick, focused, and to the point

- Ask what not how

- Talk about how problems will hinder accomplishments

- Show them how they can succeed

"With Influential people

- Be social and friendly with them, building the relationship

- Listen to them talk about their ideas

- Help them find ways to translate the talk into useful action

- Don't spend much time on the details

- Motivate them to follow through to complete tasks

- Recognize their accomplishments

"With Steady people

- Be genuinely interest in them as a person

- Create a human working environment for them

- Give them time to adjust to change

- Clearly define goals for them and provide ongoing support

- Recognize and appreciate their achievements

- Avoid hurry and pressure

- Present new ideas carefully

"With Conscientious people

- Warn them in time and generally avoid surprises

- Be prepared. Don't ad-lib with them if you can

- Be logical, accurate and use clear data

- Show how things fit into the bigger picture

- Be specific in disagreement and focus on the facts 
- Be patient, persistent and diplomatic."

DISCpowerpoint@yahoo.com has another way describing the four relational styles.

A. Description

1.) Dominant

- Independent, persistent, direct. Energetic, busy, fearless.

- Focus on own goals rather than people.

- Tell rather than ask.

- Ask 'What?'

2.) Influential

- Social, persuasive, friendly. Energetic, busy, optimistic, distractible.

- Imaginative, focus on the new and future.

- Poor time managers. Focused on people than tasks.

- Tell rather than ask.

- Ask 'Who?'

3.) Steady

- Consistent, like stability. Accommodating, peace-seeking.

- Like helping and supporting others. Good listeners and counselors.

- Close relationships with few friends.

- Ask, rather than tell.

- Ask 'How?' and 'When?'

4.) Conscientious

- Slow and critical thinker, perfectionist. Logical, fact-based, organized, follows rules.

- Don't show feelings. Private. Few, but good friends.

- Big-picture, outlines.

- Ask 'Why?' and 'How?'

B. Leadership Perspective

1.) Dominant/Hawks/Boss Type

- Communicate directly and succinctly. Tell them what needs to be done, but let them figure out how best to do it. Give them choices and options. Let them control.

- Excellent at multi-tasking and can handle many projects at once. They thrive on pressure and change, and have low tolerance for boredom.

- Great builders, creators, generators of ideas for the future - they do not like long term "maintenance" projects.

- Prefer where they are in charge.

2.) Influential/Peacocks/Mover

- Want and need a lot of attention. It always best to give them your full attention. They love to talk and share their thoughts.

- Needs a lot of freedom and autonomy.

- Needs lots of changes easily bore, high energy.

- Imagination and creativity, bring out the best in people with their vision and contagious enthusiasm.

- Natural "cheerleaders".

3.) Steady/Dove/Peace Makers

- Agreeable and relax - they don't respond well to confrontation or conflict.

- Give plenty of time adjust to change. Don't hurry or confront them, if you can avoid it.

- Want and need to feel included. Be polite and thoughtful. Considerate of their feeling.

- Natural team players and are valuable asset to any group. Work well with others.

- Very sensitive and care deeply what other people think of them. 
- "Solid Citizens" Committed to goals and sharing in the fruits of success.

4.) Conscientious/Owls/Perfection

- Tell them exactly what you do and when.

- Quality control - It will be done right.

- They take pride in being practical and sensible.

- Do not be vague, emotional, inconsistent, or irrational.

- They will make sure all the t's have been crossed and I's dotted.

- Need time to adjust to change.

- Need to be given autonomy and exercise their best professional judgment.

- Compliment and they give you first rate result.

C. Communication Tips
1.) for Dominant Style

- Provide direct answers.

- Be brief, to the point.

- Concentrate on results.

- Agree with ideas, not person.

- Avoid technicalities.

- Be prepared for terse remarks.

- Use action verbs.

- Stress logic, not emotion.

- Be on time.

- Be fast-paced.

- Make eye contact and keep posture erect.

- Deliver firm handshake.

- Be organized.

- Present ideas logically and quickly.

- Ask for decision.

2.) for the Influential Style

- Be Relaxed and friendly.

- Use enthusiasm.

- Build in enjoyment and fun.

- Involve them (keep the conversation interactive).

- Don't dwell on details.

- Offer ideas to transfer talk into action.

- Use humor to be effective.

- Focus on big picture first.

- Improve tolerance for chit-chat.

- Refocus frequently and gently.

- Be alert for exaggeration.

- Be prepared for emotion.

- Support ideas with real-life testimonials.

3.) for Steady Style

- Be warm and sincere.

- Show concern for the individual.

- Be patient and stay calm.

- Minimize any risk.

- Build Teamwork. 
- Avoid high pressure.

- Offer support.

- Draw out their opinions.

- Speak in natural, relaxed tone.

- Avoid judging

- Ask open-ended questions and wait for answers

- Create a secure environment.

- Maintain ongoing contact.

- Be practical.

4.) for Conscientious Style

- Have correct information.

- Provide pros and cons.

- Give precise explanations.

- Disagree with facts, not person.

- Be diplomatic.

- Be persistent.

- Have plenty of references.

- Review recommendations.

- Have everything in writing.

- Prepare for technical questions.

- Understand their curiosity (may sound like negativity).

- Be punctual.

- Allow them to proceed slowly.

- Let them formulate their own decision.

- Expect them to analyze everything.

- Be organized and neat."

Solving the People Puzzle (1999) lines up the strengths and weaknesses of each relational style. The book emphasizes that knowing the relational style of the people around us is the key in understanding them. Also, it suggests ways in which to complement those people's strengths and weaknesses.

1.) Dominant

Table 4. Summary of Strengths and Weaknesses of Dominant Type

\begin{tabular}{|l|l|}
\hline \multicolumn{1}{|c|}{ Strengths } & \multicolumn{1}{c|}{ Weaknesses } \\
\hline Gets things done & Insensitive toward others \\
Persistent & Overlooks risks and cautions \\
Takes charge & Takes on too much \\
Accepts challenges & Too demanding of others \\
Makes quick decisions & Impatient \\
Solves practical problems & Inflexible to detail \\
Self-reliant & Resents restrictions \\
Works hard & \\
\hline
\end{tabular}

2.) Influential 
Table 5. Summary of Strengths and Weaknesses of Influential Type

\begin{tabular}{|c|c|}
\hline Strengths & Weaknesses \\
\hline Optimistic & Lacks follow-through \\
Personable & Talks too much \\
Verbally articulate & Acts impulsively \\
Entertaining & Over-commits \\
Enthusiastic & Misjudges capabilities \\
Makes a good impression & Overestimates results \\
Persuasive & Jumps to conclusions \\
Outgoing and friendly & Verbally manipulative \\
\hline
\end{tabular}

3.) Steady

Table 6. Summary of Strengths and Weaknesses of Steady Style

\begin{tabular}{|c|c|}
\hline Strengths & Weaknesses \\
\hline Supportive & Resists quick change \\
Loyal & Overly tolerant \\
Consistent & Indecisive \\
Reliable & Indirect with others \\
Agreeable & Difficulty with deadlines \\
Service-oriented & Procrastinates \\
Good listener & Avoids conflict \\
Builds relationships & Lacks initiative \\
\hline
\end{tabular}

4.) Conscientious

Table 7. Summary of Strengths and Weaknesses of Conscientious Type

\begin{tabular}{|c|c|}
\hline Strengths & Weaknesses \\
\hline Orderly & Overly cautious \\
Self-disciplined & Too rigid \\
Thorough & Lacks spontaneity \\
Analytical & Sensitive to criticism \\
Competent & Too detail-oriented \\
Precise & Fault-finding \\
Diplomatic & Suspicious \\
Committed to quality & Pessimistic \\
\hline
\end{tabular}

Here are other models on similar theories:

Table 8. Similar Models to DISC

\begin{tabular}{|l|l|l|l|}
\hline \multicolumn{1}{|c|}{ DISC } & \multicolumn{1}{|c|}{ Smalley/Trent } & \multicolumn{1}{c|}{ LaHaye } & OCEAN \\
\hline Dominance & Lion & Choleric & Openness \\
\hline
\end{tabular}




\begin{tabular}{|l|l|l|l|}
\hline Influence & Otter & Sanguine & Extraversion \\
Steadiness & Golden Retriever & Phlegmatic & Agreeableness \\
Conscientious & Beaver & Conscientious \\
& & Neurotism \\
\hline
\end{tabular}

styles.

Wilkes (1996) in his book "Jesus on Leadership" gave sample persons that have those relational

Paul: A Dominant Leader

"Paul's strengths could include his commitment to the task God assigned to him, his determination in tough situations, and his decisiveness. His weaknesses may include a controlling spirit and tendency to ignore people's feelings. God used Paul's dominant style to lead the next mission to carry the gospel around the world."

Barnabas: An Influencer

“The strengths of Barnabas' personality could include his outgoing nature, his enthusiasm, and his flexibility. His weaknesses might include poor follow-through and a strong need to please others."

Abraham: A Steady Leader

“Abraham's strengths include a cooperative spirit, deliberate actions, and a supportive attitude. He may be perceived to be weak because he fails to confront others, dislikes change, and is often overcompromising."

Moses: A Conscientious Leader

"Moses' strengths include his concern for justice, his attention to detail, and his high moral standards. Weaknesses of his relational style include inflexibility, rigidity, and indecisiveness."

\section{Research Design and Methodology}

This chapter contains the discussion of the research design, the respondents of the study, the data gathering procedure, the data gathering instrument, and the statistical treatment used to solve the problem posted at the beginning of the study.

\subsection{Research Design}

This study made use of descriptive design in making a research. It is effective specially when gathering data from respondents, and then correlating those data from another data that can come from primary or secondary source. In this study, a survey was conducted to obtain data about teachers' relational style, and then it was checked against efficiency rating that came primarily from the principals' record of Consolidated IPCRF.

\subsection{Population}

Thirty-two teachers and staff became the respondents for this study. Their frequency and respective status are presented on the next page.

Table 8. Respondents of the Study

\begin{tabular}{|c|c|}
\hline Status & Frequency \\
\hline Teacher I & 13 \\
\hline Teacher 2 & 4 \\
\hline
\end{tabular}




\begin{tabular}{|c|c|}
\hline Teacher 3 & 11 \\
\hline Head Teacher III & 1 \\
\hline Master Teacher I & 1 \\
\hline Principal II & 1 \\
\hline Disbursing Officer II & 1 \\
\hline Total & 32 \\
\hline
\end{tabular}

\subsection{Data Gathering Procedure}

The flowchart on the next page shows the steps undertaken to come up with the needed data that will elicit the solution to the problem posted at the beginning of the study.

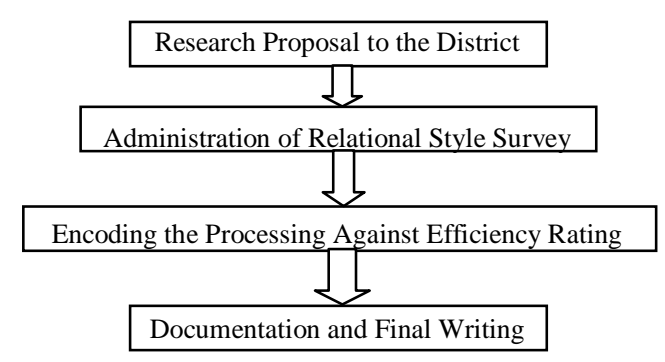

Figure 2. Flowchart of Data Gathering and Writing

\subsection{Data Gathering Instrument}

The Relational Style Survey used came from “Jesus on Leadership” by C. G. Wilkes (1996). It was presented to the principal for checking, and it was approved for administration.

For the performance evaluation, the consolidated IPCRF for the previous school year was available in the Principal's office.

\subsection{Statistical Treatment}

For the relational style and efficiency of TNHS teachers, simple mean was used to get the relational style profile.

On the other hand, F-test (ANOVA) with 5\% level of significance was used to get the possible effect of relational style to efficiency rating.

\section{Presentation, Analysis and Interpretation of Results}

This part of the study highlights the results obtained from the survey and from processing the data to get meaningful result. Analysis and interpretation follows after each table.

\subsection{TNHS Teachers' Relational Style}




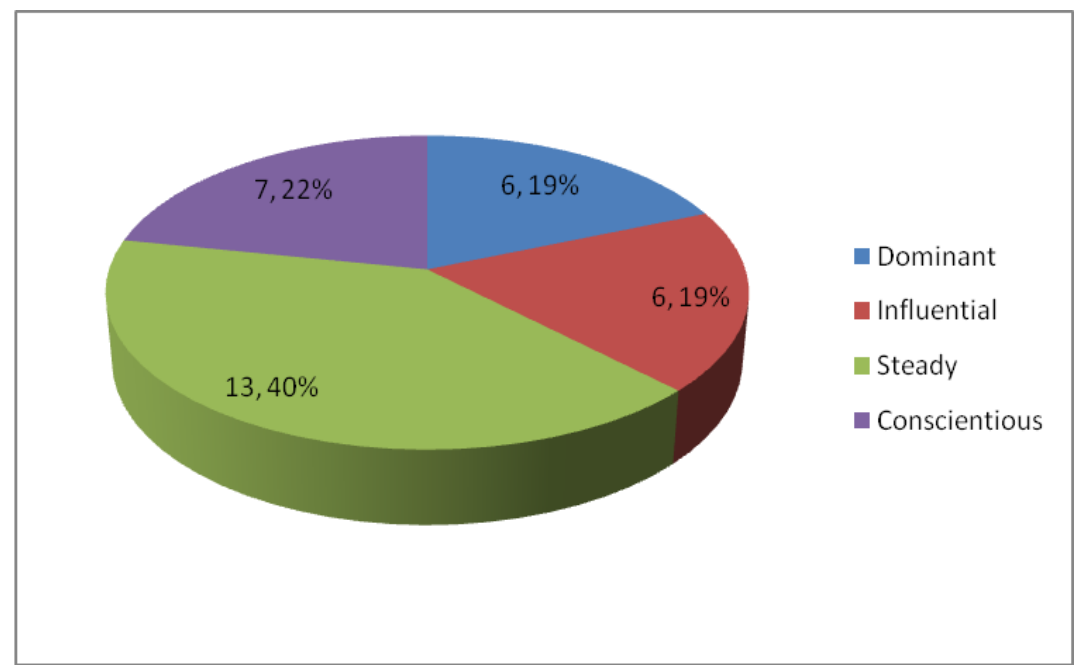

Figure 2. Relational Style of TNHS Teachers

The figure above shows the relational styles and efficiency ratings of 32 teachers of TNHS. Out of 32, six are dominant equivalent to 19\%), six are influential (equivalent to 19\%), 13 are steady (equivalent to $40 \%$ ), and 7 are conscientious (equivalent to 22\%). It can be seen that most of the TNHS teachers have a Steady relational style, which means that most of them are supportive and obedient. This doesn't mean that other teachers are not supportive or obedient. It just shows that the outstanding characteristics of most of the teachers is Steady, in terms of relational style.

\subsection{TNHS Teachers' Efficiency Rating}

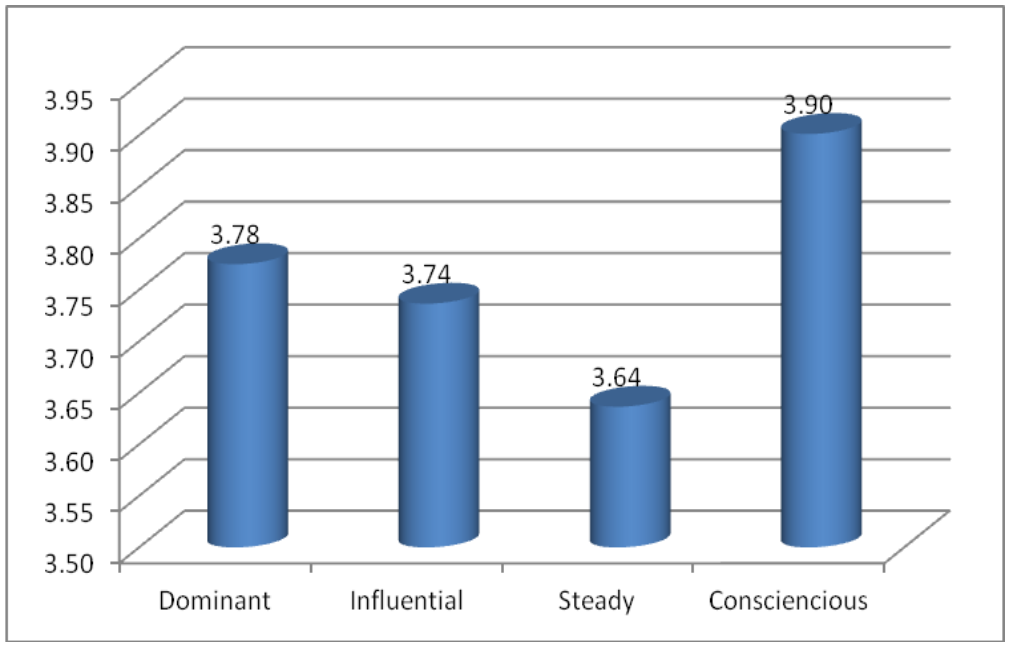

Figure 3. Efficiency Rating of TNHS Teachers

The figure above shows the mean efficiency rating of the teachers, when grouped according to their relational style. The mean efficiency rating of the dominant teachers is 3.78 , influential teachers is 
3.74, steady teachers is 3.64, and conscientious teachers is 3.90. All of these rating has an equivalent verbal interpretation of "very satisfactory." It can be seen from the figure that the conscientious group got the highest mean efficiency rating among the four groups. This can be explained how conscientious people can be described - they are organized, have logical thinking, have proper follow through, disciplined and critical in thinking.

\subsection{F-Test of Efficiency Ratings of the Four Relational Styles}

Table 10. F-test Result

SUMMARY

\begin{tabular}{lrrrr}
\hline \multicolumn{1}{c}{ Groups } & Count & \multicolumn{1}{c}{ Sum } & Average & Variance \\
\hline Dominant & 6 & 22.65 & 3.775 & 0.04675 \\
Influential & 6 & 22.42 & 3.736667 & 0.027347 \\
Steady & 13 & 47.276 & 3.636615 & 0.011346 \\
Conscientious & 7 & 27.31 & 3.901429 & 0.067381 \\
\hline
\end{tabular}

ANOVA

\begin{tabular}{|c|c|c|c|c|c|c|}
\hline $\begin{array}{l}\text { Source of } \\
\text { Variation }\end{array}$ & SS & df & MS & $\mathrm{F}$ & $\mathrm{P}$-value & F crit \\
\hline Between Groups & 0.328762 & 3 & 0.109587 & 3.368525 & 0.032419 & 2.946685 \\
\hline Within Groups & 0.910916 & 28 & 0.032533 & & & \\
\hline Total & 1.239678 & 31 & & & & \\
\hline
\end{tabular}

The table in the previous page shows the F-test result of the ratings of the different relational styles. The relational style with the highest mean efficiency rating is conscientious (3.90). Next to conscientious is dominant with a mean of 3.78, then next is influential with a mean of 3.74, and last is steady with a mean of 3.64. The F-value of 3.67 is greater than the F-crit which is 2.95. Because of this, the null hypothesis that relational style has nothing to do with efficiency rating is rejected. Relational style has significant effect to efficiency rating. If a teacher is conscientious, according to this study, he or she is likely to have a high efficiency rating. The result can be reasoned out that because conscientious persons are organized, always consider details, and plan well, they will have higher efficiency rating than the rest.

\section{Summary, Conclusions and Recommendations}

This chapter recapitulates the main points of the study, emphasizes the conclusions made as a result of the findings, and gives recommendations that help faculty and staff gain professional development with regards to relational style and efficiency rating. 


\subsection{Summary of Findings}

This study dwelt on two important variables and on the possible effect of one variable to the other: the relational style of teachers and their efficiency rating. The findings that came out on those variables are enumerated here:

a.) For the relational style of TNHS teachers - It was found out that 6 out of 32 teachers or $19 \%$ is dominant, 6 teachers or $19 \%$ are influential, 13 teachers or $40 \%$ are steady, and 7 teachers or $22 \%$ are conscientious.

b.) For the efficiency rating - It was found out that the average efficiency rating for dominant teacher is 3.78 (VS), for influential teachers is 3.74 (VS), for steady teachers is 3.64 (VS) and for conscientious teachers is 3.90 (VS).

c.) F-test - The F-value computed is 3.37 while the critical value is 2.95 .

5.2. Conclusion

Base on the findings of this study, the following conclusions were formed:

a.) That most of the TNHS teachers exhibit steady relational style;

b.) That those teachers with conscientious relational style has the highest average efficiency rating; and

c.) That relational style of teachers has something to do with their efficiency rating. If the teacher is conscientious, he or she is most likely to have a high efficiency rating.

\subsection{Recommendations}

The following recommendations were coined and suggested to the following groups of persons as a result of the findings and conclusions made on this study:

1.) Teachers - TNHS teachers should develop their versatility through overcoming their weaknesses and in enhancing their strengths.

2.) School Administration - Members of the administrative staff should plan and conduct seminars and workshops that will tap teachers planning and organizing ability.

3.) Future Researchers - Further study should be made, if not to strengthen the findings in this study, to explore more on the topic of relational style. suggested:

The following communication tips presented on DISCpowerpoint@yahoo.com is now being

1.) Use These Words With Dominant Type - Consider, choices, options, opportunities, bottom line, results, expedient, effective, growth, develop, win, gain

2.) Use These Words With the Influential Type - Share, let's, we, enjoy, easy, flexible, big picture, creative, popular, fun, relaxing, relationship, family, recognition, motivation, friendship, teamwork, partners, communication,

3.) Use These Words With Steady Type - Safe, secure, comfortable, appreciate, timing, harmony, cooperation, need, help, step-by-step, values, traditions, respect, schedules, timely, punctual, consistent

4.) Use These Words With the Conscientious Type - Accurate, right, correct, precise, plan, research, quality, economical, structured, logical, proven, clarity, details, perfect, policies, procedures, guaranteed, cohesive. 


\section{References}

Arthur, W., Bennett, W., Edens, P. S., \& Bell, S. T. (2003). Effectiveness of training in organizations: A meta-analysis of design and evaluation features. Journal of Applied Psychology, 88(2), 234-245.

Blue Mountain Arts. (1999). Teaching and Learning Are lifelong Journeys. Boulder, Colorado.

Desimone, L. M. (2009). Improving impact studies of teachers' professional development: Toward better conceptualizations and measures. EducationalResearcher, 38(3), 181-199. doi: 10.3102/0013189X08331140

Hill, H. (2009). Fixing teacher professional development. Phi Delta Kappan, 90(7), 47-476.

Kelly, T. (2012). Restructure Staff Development for Systemic Change. Contemporary Issues inEducation Research, 5, 105-108.

Learning Forward. (2011). Standards for Professional Learning. Oxford, OH: Author.

Mizell, H., Hord, S., Killion, J., \& Hirsh, S. (2011). New standards put the spotlight on professional learning. Journal of Staff Development, 32(4), 10-14.

Solving the People Puzzle. (1999). Walk Thru the Bible Ministries, Inc. U.S.A

Sparks, D., \& Hirsh, S. (2000). Strengthening professional development. EducationWeek, 19(37), 42.

Supovitz, J. A., \& Turner, H. M. (2000). The effects of professional development onscience teaching practices and classroom culture. Journal of Research in Science Teaching, 37(9), 963-980.

Villegas-Reimers, E. (2003). Teacher Professional Development: An International Review of the Literature. Paris, France: International Institute for Educational Planning

Wilkes, C. G. (1996). Jesus on Leadersip. Life Way Press. Makati City. 